\title{
Meteorological Table
}

\section{Dr. Clarke}

To cite this article: Dr. Clarke (1811) Meteorological Table , Philosophical Magazine Series 1, 37:156, 319-319, DOI: 10.1080/14786441108563292

To link to this article: http://dx.doi.org/10.1080/14786441108563292

$$
\text { 曲 Published online: } 18 \text { May } 2009 .
$$

Submit your article to this journal 전

LII Article views: 2

Q View related articles $\asymp$ 
Meteorological Table, by Dr. ClaRKE, of Nottingham.

\begin{tabular}{|c|c|c|c|c|c|c|c|c|c|c|c|c|c|}
\hline \multicolumn{4}{|c|}{ Thermometer. } & \multicolumn{4}{|c|}{ Barometer. } & \multicolumn{2}{|c|}{ Weather. } & \multicolumn{4}{|c|}{ Winds. } \\
\hline 苞 & 焉 & 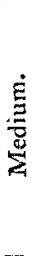 & 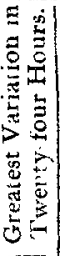 & 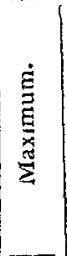 & 晃 & 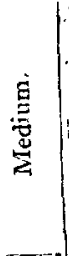 & 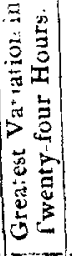 & .تี & $\sum_{3}^{+}$ & 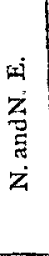 & 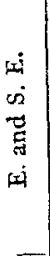 & 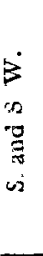 & $\begin{array}{l}3 \\
z \\
\dot{Z} \\
3 \\
3\end{array}$ \\
\hline 53 & 18 & 36 & 10 & $311 \cdot 36$ & $29 \cdot 75 \mid$ & $301 \cdot 15$ & 0.09 & 206 & 5 & 5 & 9 & 17 & 8 \\
\hline $5+$ & 14 & 37 & 16 & 0.34 & $\mid 28.75$ & $99 \times 75$ & $0.68 \mid$ & 19 & 9 & 7 & 4 & 21 & 7 \\
\hline 59 & 30 & 43 & 10 & $: 0 \cdot 10$ & $98 \cdot 98$ & 29.30 & $(1) 41$ & 19 & 12 & 17 & 9 & 14 & 11 \\
\hline 70 & 32 & 47 & 9 & $30 \cdot 18$ & $29 \cdot 27$ & $29 \cdot 7:$ & 033 & 24 & i & 14 & 7 & 18 & 2 \\
\hline 68 & 29 & 47 & 15 & $303 \%$ & $49 \cdot 4 \cdot 5$ & $29 \cdot 86$ & 1.05 & 2.5 & 8 & 26 & 4 & 7 & 6 \\
\hline 78 & 38 & 57 & 10 & $30 \cdot 35$ & 29.72 & 30.38 & $(1.35)$ & 28 & 2 & 16 & 7 & 15 & 4 \\
\hline 77 & 48 & 57 & 15 & 2995 & $29 \cdot 40$ & 29.75 & 0.31 & 12 & 19 & 9 & 4 & 12 & 5 \\
\hline 80 & 40 & 57 & 14 & $10 \times 43$ & $39 \cdot 39$ & 129.79 & 0.52 & 21 & 10 & 1 & 6 & 18 & 6 \\
\hline 89 & 39 & 56 & 11 & $130 \cdot 38$ & $24 \cdot 71$ & $30 \cdot 10$ & 0.31 & 23 & $\mathscr{2}$ & 17 & 6 & 10 & 5 \\
\hline 68 & 24 & 45 & 8 & $30 \cdot 30$ & $29 \cdot 03$ & $29 \cdot 86$ & $(0.54$ & 23 & 8 & 15 & 11 & 8 & 6 \\
\hline 53 & 26 & 38 & 10 & $30 \cdot 12$ & & $29 \cdot 44$ & 0.55 & 25 & $\tilde{5}$ & 11 & 10 & 8 & 7 \\
\hline 50 & 19 & 36 & 10 & 30.50 & 28.85 & $29 \cdot 62$ & 0.71 & 21 & 10 & 5 & 2 & 9 & 21 \\
\hline & & & & & & & & & & & & & \\
\hline
\end{tabular}

\section{ANNUAL RESULTS AT NOTTINGHAM.}

Thermometer.

WIND.

Highest Observation, September $2 \mathrm{~d} \quad \ldots \ldots \ldots 2^{\circ} \mathrm{E}$.

Lowest Observation, February 20 th $\ldots \ldots \ldots \ldots$.... $14^{\circ} \mathrm{NE}$.

Greatest Variation in Twenty-four Hours, February 19-20 $16^{\circ}$

Annual Mean $\ldots . . \ldots 6^{\circ}$

Barometer. WIND.

Highest Observation, December 31st $\quad \ldots \ldots \ldots \ldots$.... $3050 \mathrm{NE}$.

Lowest Observation, February 19th $\quad \ldots . \ldots . . . . .28 .735$.

Greatest Variation in Twenty-four Hours, May 20th .... 10.5

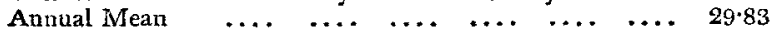

Weather. Days. Winds. Times. Jain. Jnches.

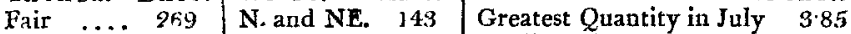

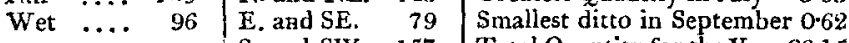

\begin{tabular}{|c|c|}
\hline 365 & $\begin{array}{l}\text { S. and SW. } 157 \\
W . \text { and NW. } 88\end{array}$ \\
\hline & 467 \\
\hline
\end{tabular}

Total Quantity for the Year 23.16

The Barometer is firmly fixed to a standard wall on an elevation of 130 feet, and the Pluviameter is placed in a garden 140 feet from the level of the sea. 